\title{
Influence of temperature on high molecular weight poly(lactic acid) stereocomplex formation
}

\author{
M. Hortós ${ }^{1,2}$, M. Viñas ${ }^{1}$, S. Espino ${ }^{2}$, J. J. Bou ${ }^{1 *}$ \\ ${ }^{1}$ Universitat Politècnica de Catalunya/ETSEIB/Departament d'Enginyeria Química. Avinguda Diagonal, 647, \\ 08028 Barcelona, Spain \\ ${ }^{2}$ Ercros S.A., Departamento de I+D. Avinguda Diagonal, 595, 08014 Barcelona, Spain
}

Received 7 June 2018; accepted in revised form 4 September 2018

\begin{abstract}
The influence of temperature on the formation of high molecular weight poly(lactic acid) (PLA) stereocomplex was studied by evaluation of the precipitates from dioxane solutions of PLA enantiomers (PLLA and PDLA). The racemic mixtures were characterized by Gel Permeation Chromatography, Infrared Spectroscopy, Differential Scanning Calorimetry, Scanning Electronic Microscopy, Wide-Angle X-ray Scattering and Vicat Softening Temperature. Precipitation was carried out under different solution temperatures, keeping constant the mixing ratio $\left(X_{\mathrm{D}}\right)$, the molecular weight, the optical purity of both PLA enantiomers and the stirring rate. It was found that the precipitates contained only pure stereocomplex crystallites (racemic crystallites), without observing crystal phase separation between both homocrystals. The kinetics of the insoluble phase formation could be adjusted with the Avrami model, classically used for polymer crystallization in molten state. It was observed that the maximum PLA stereocomplex production rate was at about $40^{\circ} \mathrm{C}$. However, more thermally stable racemic crystallites were formed at high solution temperatures. It was found that all the precipitates were sphere-like at $10 \mathrm{~g} \cdot \mathrm{dl}^{-1}$ at the solution temperature of $25,40,60$ and $80^{\circ} \mathrm{C}$.
\end{abstract}

Keywords: biodegradable polymers, polylactide, polymeric racemic mixture, crystal growing, capillary rheometry

\section{Introduction}

Poly(lactic acid), or PLA, which belongs to the family of linear polyesters, is industrially produced via Ring Opening Polymerization (ROP) of the cyclic dimer of lactic acid (lactide), which is made from the fermentation of dextrose, a renewable feedstock available from sugar or corn, among others [1, 2].

Processing, crystallization, final properties and degradation behaviour of PLA are all strongly influenced by the structure and composition of the polymer chains, specifically the ratio of the L- and D-isomer of lactic acid [3-7]. This stereochemical structure of PLA can be tuned by copolymerization of mixtures of L-lactide and meso-, D-, or rac-lactide resulting in high molecular weight amorphous or semicrystalline polymers with a melting temperature from
130 to $185^{\circ} \mathrm{C}[8,9]$. Isotactic PLLA or PDLA homopolymers (comprising only L-lactide and D-lactide, respectively) are semicrystalline materials with the highest melting point, while PLA copolymers with low optical purity (relative proportion of the major PLA enantiomer) show lower melting points and dramatically slower crystallization rate. Finally, they become fully amorphous at proportions above $12 \%$ of the other PLA enantiomer $[6,7,10]$.

PLA has experienced strong market growth over the last decades in comparison with other widely used petroleum-based plastics due to its bio-based and biodegradability nature [2] and its good technical properties [11-13]. Because of its high potential replacement to petrochemical plastics in many applications such as packaging, bio-medical area and

$\overline{{ }^{*} \text { Corresponding author, e-mail: jordi.bou@upc.edu }}$ (C) BME-PT 
agriculture [14] and its viability at industrial scale, this bioplastic has been extensively studied [15-19]. However, some of PLA deficiencies such as low thermal resistance and low melt strength limit the use of this polymer in some industrial areas. Increasing the crystallization rate of PLA could be a way to improve the thermal properties due to, in its amorphous form, the range of applications is severely restricted by its low glass transition temperature $\left(55^{\circ} \mathrm{C}\right)$.

Another strategy to obtain a high thermal resistance material is blending both PLA enantiomers (PLLA and PDLA). The interaction between them prevails and a stereoselective association of the former polymer pair takes place. Such association is described as stereocomplexation or stereocomplex formation and a new crystalline structure, induced by hydrogen bonds and Van der Waal forces, is formed [20, 21]. Several studies about PLA stereocomplexation have been carried out [22-27]. These new crystallites (scPLA) have a melting point $50^{\circ} \mathrm{C}$ greater than the homocrystallites of PLLA or PDLA, thus this material is by itself interesting in terms of heat resistance (view Table 1).

PLA stereocomplexation could take place in the absence of a solvent (in bulk: crystallization from the melt or during polymerization), or in the presence of solvent (in solution) [29]. However, in bulk blending, when the molecular weights of PLA reach a critical value (such as $6 \mathrm{~kg} \cdot \mathrm{mol}^{-1}$ for the PLLA/PDLA blends [30]), both PLA homo and stereocomplex crystallites would develop, and the phase separation between PLLA and PDLA would occur due to the restrained mobility of polymers chains [24, 31].

The synthesis of the sc-PLA in solution is a potential alternative to the bulk procedure in order to obtain poly(lactic acid) stereocomplex with only racemic crystallites even for high molecular weight polymers. They can be formed when the polymer concentration in a solution exceeds a critical value, which depends on several factors such as the solvent, the molecular weight, the solution temperature, among others [29]. In this circumstance, the stereocomplex

Table 1. Thermal properties for semicrystalline and stereocomplex of PLA [28].

\begin{tabular}{|ll|c|c|}
\hline & & Semicrystalline PLA & sc-PLA \\
\hline$T_{\mathrm{g}}$ & {$\left[{ }^{\circ} \mathrm{C}\right]$} & $55-60$ & $60-70$ \\
\hline$T_{\mathrm{m}}$ & {$\left[{ }^{\circ} \mathrm{C}\right]$} & $160-180$ & $200-240$ \\
\hline HDT-B & {$\left[{ }^{\circ} \mathrm{C}\right]$} & $100-150$ & $160-200$ \\
\hline
\end{tabular}

crystallization starts and the solution of both PLA enantiomers, initially transparent, becomes turbid due to the PLA precipitates formation. According to Tsuji [29], the critical concentration for PLA stereocomplex crystallite formation is much lower than that for homo-crystallite formation of either PLLA or PDLA (homo-crystallization). The yield of PLA stereocomplexation in solution depends on many factors such as the optical purity and molecular weight of PLA enantiomers, the polymer concentration, the ratio of PDLA $\left(X_{\mathrm{D}}\right)$, the solvent, the solution temperature and the stirring rate [22].

The aim of this work was to obtain a high molecular weight sc-PLA by precipitation after blending PLLA and PDLA in dioxane without observing crystal phase separation between both homocrystals, PLLA and PDLA. Another objective of this paper was to study the influence of the solution temperature on the kinetics of the PLA stereocomplex formation and on the quality of the racemic crystallites produced. The hypothesis contemplated was that at higher temperatures the chain mobility increases and thus it is possible to obtain more thermally stable PLA stereocomplex crystallites.

The PLA stereocomplexation process was followed by Infrared Spectroscopy, Differential Scanning Calorimetry, Scanning Electronic Microscopy, WideAngle X-ray Scattering and Vicat Softening Temperature. Precipitation was carried out under different solution temperatures, keeping constant the PLA concentration the mixing ratio $\left(X_{\mathrm{D}}\right)$, the molecular weight and optical purity of both PLA enantiomers and the stirring rate.

\section{Experimental}

\subsection{Materials}

Both poly(L-lactic acid) (PLLA) and poly(D-lactic acid) (PDLA) were semicrystalline and high molecular weight polymers (140 and $120 \mathrm{~kg} \cdot \mathrm{mol}^{-1}$, respectively) with an optical purity above $99,5 \%$ for each PLA enantiomer and were kindly supplied by Ercros S.A. (Barcelona, Spain). The molecular weights were measured by GPC. The glass transition and melting temperature of both PLA enantiomers is 55 and $178^{\circ} \mathrm{C}$, respectively. Anhydrous 1,4-Dioxane stabilized with 25 ppm of BHT (3,5-Di-tert-butyl-4hydroxytoluene) was used as a solvent and supplied by Scharlab (Barcelona, Spain). It was used as received without any purification. Table 2 shows the designation, commercial brand name, number average 
Table 2. PLA enantiomers: designation, commercial brand name, number average molar mass, polydispersity and optical purity.

\begin{tabular}{|l|c|c|}
\hline \multicolumn{1}{|c|}{ Designation } & PLLA & PDLA \\
\hline Brand name & ErcrosBio $^{\circledR}$ LL650 & ErcrosBio $^{\circledR}$ LD600 \\
\hline$M_{\mathrm{n} \quad\left[\mathrm{kg} \cdot \mathrm{mol}^{-1}\right]}$ & 110 & 70 \\
\hline Polydispersity, $D$ & 2.31 & 2.37 \\
\hline Optical purity $\quad[\%]$ & $>99.5$ & $>99.5$ \\
\hline
\end{tabular}

molar mass, polydispersity and optical purity of both poly (lactic acid) enantiomers used in this study.

\subsection{Stereocomplex preparation}

PLA precipitates were obtained by the following method. Both PLA enantiomers were dried in an oven at $80^{\circ} \mathrm{C}$ for 8 hours to prevent the polymer from degradation by hydrolysis during the experiment. Once the granules of each polymer enantiomer were dried they were dissolved in dioxane separately at $10 \mathrm{~g} \cdot \mathrm{dl}^{-1}$ warming if necessary, and obtaining after 4-8 hours a viscous and transparent solution. After heating to the desired temperature, equal volumes of each solution containing the enantiomers were mixed and maintained under magnetic stirring in a closed and thermostated recipients of $100 \mathrm{ml}$ for 16 days. The expected polymer mixing ratio was $1: 1$. Process temperatures $\left(T_{\mathrm{c}}\right)$ were $25,40,60$ and $80^{\circ} \mathrm{C} .2 \mathrm{ml}$ aliquots were taken daily and centrifuged for one hour at $T_{\mathrm{c}}$ in thermostatized oven, in order to separate the insoluble phase from the solution. The precipitate was then cleaned with fresher dioxane at $T_{\mathrm{c}}$ to remove the non-complexed single polymers. Supernatant liquid samples were recovered and dried, to obtain the soluble phase $(S P)$ specimens, usually as transparent to translucent films. Before characterization, the precipitates (insoluble phase or $I P$ ) and the $S P$ samples were dried for 10 days in air and finally in vacuum at $60^{\circ} \mathrm{C}$. IP precipates, prepared at the indicated temperatures, were obtained as a white powder and used without further handling. All samples were weighted up to $0.1 \mathrm{mg}$ precision using a calibrated electronic balance.

\subsection{Testing bars preparation}

Once the precipitates were dried they were compressed in a Gumix LP 250/200 (Cornellà, Spain) at $200^{\circ} \mathrm{C}$ and $20 \mathrm{MPa}$ for 15 minutes in order to obtain the test bars by sintering, according to the method developed by Bai et al. [32]. The compression temperature was set $30^{\circ} \mathrm{C}$ lower than the melting temperature of the precipitates in order to prevent the sc-PLA crystallites from melting during processing.

\subsection{Characterization methods}

The average molar masses and the polydispersity of the specimens were measured by SEC using a Waters Gel Permeation Chromatography (GPC) apparatus equipped with a Waters 410 differential refractive index (Milford, MA, USA) and an Agilent ultraviolet detector (Santa Clara, CA, USA). The analyses were developed at $25^{\circ} \mathrm{C}$ and $0.8 \mathrm{ml} \cdot \mathrm{min}^{-1}$ in hexafluoroisopropanol (HFIP) from Apollo Sci (Bradbury, UK) on a PLgel column from Polymer Laboratories Ltd (Palo Alto CA, USA) with $10 \mu \mathrm{m}$ particle size. The calibration was performed with PMMA standards from 2000 to $500 \cdot 10^{3} \mathrm{~g} \cdot \mathrm{mol}^{-1}$ from Sigma (Saint Louis, MO, USA).

The chemical structure was evaluated by Infrared Spectroscopy (IR) with a PerkinElmer model Spectrum Two with a UATR unit (Waltham, MA, USA). The study was carried out after and before mixing both enantiomeric PLA samples with the objective to find out the differences in the spectrums due to stereocomplex crystallites formation.

A TA Q1000 (New Castle, DE, USA) differential scanning calorimeter (DSC) was used to study the thermal properties of the PLA precipitates, in particular the fusion behaviour of the racemic crystallites synthesized at different solution temperatures. Samples of 6-8 mg were taken from the PLA precipitates and sealed in aluminium pans. All samples were heated from 30 to $250^{\circ} \mathrm{C}$ at a heating rate of $10^{\circ} \mathrm{C} \cdot \mathrm{min}^{-1}$ under a nitrogen flow of $30 \mathrm{ml} \cdot \mathrm{min}^{-1}$. Crystallinity degree of PLA stereocomplex was calculated by Equation (1):

$X_{\mathrm{C}, \mathrm{sc}}=\frac{\Delta H_{\mathrm{m}, \mathrm{sc}}}{\Delta H_{0, \mathrm{sc}}}$

where $\Delta H_{\mathrm{m}, \mathrm{sc}}$ is the melting enthalpy of stereocomplex crystals $\left[\mathrm{J} \cdot \mathrm{g}^{-1}\right]$ and $\Delta H_{0, \mathrm{sc}}$ is the theoretical melting enthalpy value for a $100 \%$ stereocomplex crystalline PLA, estimated in $142 \mathrm{~J} \cdot \mathrm{g}^{-1}$ [33].

The crystalline structure of the PLA stereocomplex crystallites were investigated by WAXS in the Barcelona Research Center in Multiscale Science and Engineering. It was carried out on powder samples of the racemic crystallites from the insoluble phase synthetized at different temperatures of mixing by means of a Bruker D8 Advance model (Billerica, MA, USA) powder diffractometer with 
$\mathrm{Cu} \mathrm{K} \alpha$ radiation of wavelength $k=0.15406 \mathrm{~nm}$. A range of $2 \theta$ from 10 to $30^{\circ}$ was recorded, by a step size of $0.02^{\circ}$ per second.

The morphology of the racemic crystallites of PLA was observed using a Scanning Electronic Microscope (SEM) JEOL JSM-7001F (Peabody, MA, USA) coated with Pt/Pd: $80 \% / 20 \%$.

Samples were sintered for determining the Vicat softening temperature at which a flat-ended needle penetrated $1 \mathrm{~mm}$ into the sample at a specific load of $5 \mathrm{~kg}$ (Vicat-B). The test was performed in a JBA 687-A4 model (Cabrils, Spain). Methyl silicone was used in an oil bath at a heating rate of $50^{\circ} \mathrm{C} \cdot \mathrm{h}^{-1}$.

The evaluation of the viscosity of the precipitates formed at $25^{\circ} \mathrm{C}$ was determined by a Rosand RH2000 (Malvern, UK) capillary rheometer with a capillary length and diameter of 16 and $0.5 \mathrm{~mm}$, respectively.

\section{Results and discussion}

\subsection{Effect of the stereocomplex synthesis on the molecular weight}

Dioxane has been chosen because of its high boiling temperature and low volatility. No representative losses of this solvent have been detected during the process of formation of the stereocomplex. Recovery of partial fractions of $I P$ and the final product has been developed by centrifugation and the materials sedimented easily.

Since poly(lactic acid) can suffer thermal and hydrolytic degradation [34] it was noteworthy to study by GPC the possible decrease of the molecular weight of PLA during the synthesis of stereocomplex. Table 3 shows the number average molecular weight $\left(M_{\mathrm{n}}\right)$ and the polydispersity of the precipitates synthesized at 25 and $80^{\circ} \mathrm{C}$. As it can be observed in Table 3, both precipitates presented a lower molecular weight than the arithmetic mean of the molecular weight between both enantiomers $\left(90 \mathrm{~kg} \cdot \mathrm{mol}^{-1}\right)$. With increasing the solution temperature, the precipitates presented higher degradation. In particular, the precipitate formed at $80^{\circ} \mathrm{C}$ suffered a dramatic drop. Moreover, an increase of the polydispersity of $I P$ synthesized at $25^{\circ} \mathrm{C}$ was observed,

Table 3. Number molecular weight and polydispersity of the PLA grades tested.

\begin{tabular}{|c|c|c|}
\hline PLA grade & $\begin{array}{c}\boldsymbol{M}_{\mathbf{n}} \\
{\left[\mathbf{k g} \cdot \mathbf{m o l}^{-\mathbf{1}}\right]}\end{array}$ & $\boldsymbol{D}$ \\
\hline$I P 25^{\circ} \mathrm{C}$ & 80 & 3.25 \\
\hline$I P 80^{\circ} \mathrm{C}$ & 45 & 1.92 \\
\hline
\end{tabular}

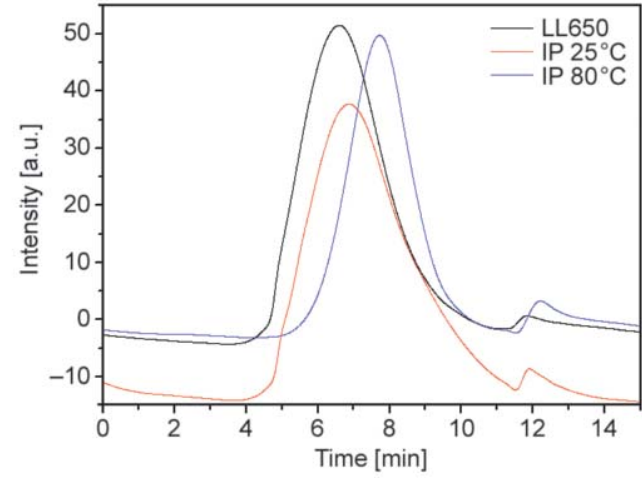

Figure 1. GPC chromatograms of LL650 and the IP synthetized at 25 and $80^{\circ} \mathrm{C}$.

while the polydispersity of the precipitate at $80^{\circ} \mathrm{C}$ decreased compared to original PLA enantiomers. This fact can be illustrated in Figure 1, which shows the three GPC chromatograms corresponding to PLA LL650 grade and the $I P$ synthesized at 25 and $80^{\circ} \mathrm{C}$, which were the lowest and highest temperatures applied in this work, respectively.

Therefore, it is assumed that the molecular weight of PLA in the precipitates did not remain constant during the synthesis and degradation increased with the solution temperature. Consequently, this fact could be relevant to justify the following results.

\subsection{Kinetic study of the sc-PLA formation}

From an industrial and productive point of view, it is important to study the influence of the temperature of mixing on the kinetics of sc-PLA formation.

Initially, the mixture between PLLA and PDLA in dioxane was homogeneous and transparent. However, after some days, a white precipitate $(I P)$ appeared, and was expected to be the sc-PLA according to Tsuji et $a l$. [22]. In order to study the kinetics of the sc-PLA formation at different temperatures, the percentage of the $I P$ was weighted over the total polymeric mass for each aliquot, according to Equation (2):

$I P[\%]=\frac{\operatorname{mass}_{\mathrm{IP}}}{\operatorname{mass}_{\mathrm{IP}}+\operatorname{mass}_{\mathrm{SP}}} \cdot 100$

where mass $_{\text {IP }}$ and mass ${ }_{S P}$ were the masses of the insoluble and soluble phases, respectively.

Differences in the kinetics of the sc-PLA formation were observed with increasing the temperature of mixing. Such behaviour is presented in Figure 2 .

The insoluble phase increased over the mixing time displaying a sigmoidal-type profile, particularly at high mixing temperatures, i.e. 60 and $80^{\circ} \mathrm{C}$. For each temperature, a similar behaviour can be observed. 


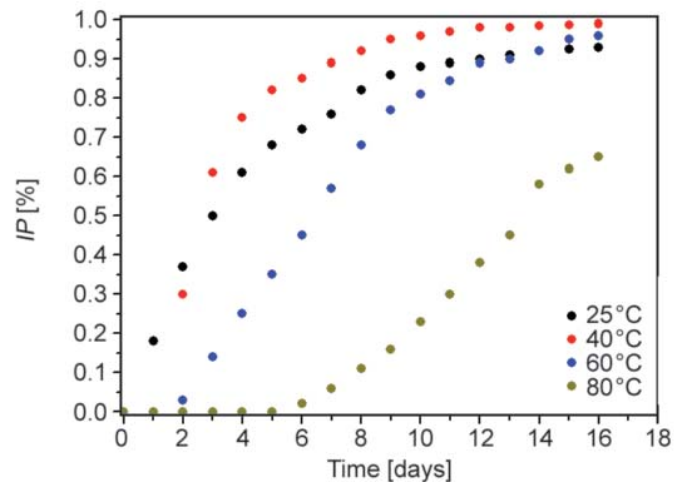

Figure 2. Evolution of the $I P$ formation over time at 25, 40, 60 and $80^{\circ} \mathrm{C}$.

Initially, the percentage of IP in the mixture is zero, subsequently followed by an induction period where the first sc-PLA nuclei are formed. For better understanding, the induction period was set in this experiment when the first precipitates were detected at each temperature. After a certain period, when the nuclei were large enough, the crystal growth started and finally reached asymptotically a maximum formation level.

On one hand, at low temperatures $\left(25\right.$ and $\left.40^{\circ} \mathrm{C}\right)$ the induction period was almost negligible because the nuclei were formed during the first hours of the experiment. Besides, the first precipitates that were observed belonged to the experiment at $25^{\circ} \mathrm{C}$ at early hours whereas the induction time for the system at $40^{\circ} \mathrm{C}$ was set at 1 day. On the other hand, at high temperatures, i.e. 60 and $80^{\circ} \mathrm{C}$, the induction period could be observed at 2 and 5 days, respectively. Therefore, the induction period increases with the mixing temperature. This trend can be explained by the fact that nucleation of sc-PLA is strongly affected by the solubility, which increases with the temperature.

Differences in the maximum percentage of IP at 16 days at each mixing temperature were detected. While the plateau levels for 25,40 and $60^{\circ} \mathrm{C}$ were similar, around $90 \%$ over the total polymeric mass, the plateau for the experiment at $80^{\circ} \mathrm{C}$ reached a value of only $65 \%$. This deviation from the other experiments could be explained by the fact that the critical PLA concentration in the $S P$ increases with the temperature, in agreement with Tsuji et al [25].., who developed a study using low molecular weight PLA When the PLLA and PDLA concentration dropped at the critical value at each temperature, the system reached equilibrium, limiting further development of PLA stereocomplexation. Another factor to take into account to understand the formation profile of the IP formed at $80^{\circ} \mathrm{C}$ is that at high temperatures PLA suffers a higher decrease of its molecular weight, as it is shown above. A decrease in the molecular weight increases the critical concentration [29], reducing the range of precipitation and thus the plateau value.

It is noteworthy to mention that the optimum temperature in terms of kinetics of the sc-PLA formation is around $40^{\circ} \mathrm{C}$ since the overall crystallization process is not only affected by solubility but also by the polymer chain mobility. With rising the temperature, the chain mobility gradually became more significance, being able to cause further rearrangements between both PLA enantiomeric forms. Moreover, solubility increases with temperature, reducing the precipitation rate, particularly at 60 and $80^{\circ} \mathrm{C}$.

It was intended to fit the experimental data to the Avrami model, which is a conventional model that explains the kinetics of polymer crystallization from melt state or dilute solutions [35]. The general Avrami law is described by Equation (3):

$X_{\mathrm{c}}=1-\exp \left(-k \cdot\left(t-t_{\text {induction }}\right)^{\mathrm{n}}\right)$

where $X_{\mathrm{c}}$ is the relative degree of crystallinity at certain crystallization time $t, n$ is the Avrami exponent depending on the nature of nucleation and the growth geometry of the crystals and $k$ is the crystallization rate constant involving both nucleation and grow rate parameters [35].

In order to estimate the Avrami parameters, the relative degree of crystallinity $\left(X_{\mathrm{c}}\right)$ was assumed as the percentage of insoluble phase (IP), and the induction period (tinduction) was presupposed as the time when the first precipitate appeared at each temperature. The linear form of this equation can be expressed as Equation (4):

$\log (-\ln (1-I P))=\log k+n \cdot \log \left(t-t_{\text {induction }}\right)$

The Avrami parameters $n$ and $k$ were obtained from the slopes and the intercepts of Equation (4), respectively. The data aligned according to Equation (4) is presented in Figure 3.

The Avrami parameters and $t_{1 / 2}$ are shown in Table 4 . As it can be observed in Figure 3 and Table 4, the experimental data properly fitted to the Avrami model with correlation coefficients of all studied systems of 0,990 or larger. Avrami exponent $n$ ranged from 0.81 to 1.68 . A maximum on the kinetic constant $(k)$ 
of the overall crystallization process was observed around $40^{\circ} \mathrm{C}$ since the overall crystallization process was affected by solubility and chain mobility.

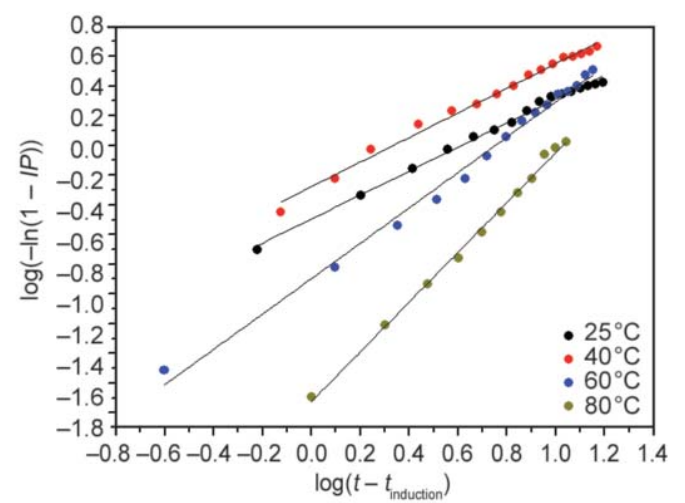

Figure 3. Experimental data aligned according to Avrami model.

Table 4. Comparison of the Avrami parameters of sc-PLA formation with the different mixing temperatures.

\begin{tabular}{|c|c|c|c|c|}
\hline $\begin{array}{c}\boldsymbol{T} \\
{\left[{ }^{\circ} \mathbf{C}\right]}\end{array}$ & $\boldsymbol{n}$ & $\begin{array}{c}\boldsymbol{k} \\
{\left[\mathbf{d}^{-\mathbf{n}}\right]}\end{array}$ & $\boldsymbol{R}^{\mathbf{2}}$ & $\begin{array}{c}\boldsymbol{t}_{\mathbf{1} / \mathbf{2}} \\
{[\mathbf{d}]}\end{array}$ \\
\hline 25 & 0.81 & 0.32 & 0.995 & 3.0 \\
\hline 40 & 0.83 & 0.53 & 0.991 & 2.6 \\
\hline 60 & 1.19 & 0.12 & 0.992 & 5.9 \\
\hline 80 & 1.68 & 0.02 & 0.997 & 13.6 \\
\hline
\end{tabular}

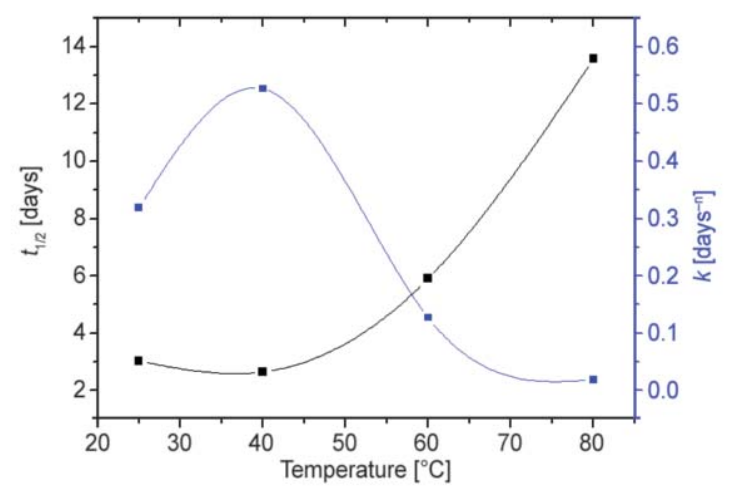

Figure 4. Evolution of $k$ and $t_{1 / 2}$ with the mixing temperature.

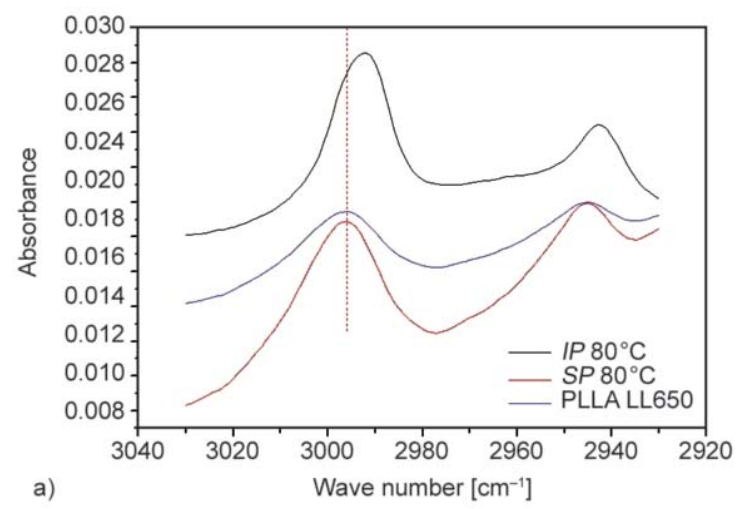

Moreover, the profile of the evolution of $k$ is asymmetric over the mixing temperature range tested. At higher temperatures, i.e. 60 and $80^{\circ} \mathrm{C}$, where nucleation of racemic crystallites was limited, the drop of the kinetic constant value was more significant than the $k$ value at $25^{\circ} \mathrm{C}$, where nucleation was favourable but the crystal growth was restricted due to its lower chain mobility.

Besides, $t_{1 / 2}$, which was defined as the time when the system reached $50 \%$ of insoluble phase over the total polymeric mass, could be calculated by means of Equation (3). The behaviour of $t_{1 / 2}$ at the different mixing temperatures was equivalent to the $k$ trend, in this case with a minimum value at $40^{\circ} \mathrm{C}$. The $k$ profiles and $t_{1 / 2}$ are depicted in Figure 4 .

\subsection{FT-IR}

The FT-IR spectra of $I P$ and $S P$ produced at $80^{\circ} \mathrm{C}$ of mixing temperature and PLLA LL650 grade in the $\mathrm{C}-\mathrm{H}$ stretching region of methyl group (a) and $\mathrm{C}=\mathrm{O}$ stretching region (b) at room temperature are presented in Figure 5. A shift to low frequencies of 2,6 and $3,5 \mathrm{~cm}^{-1}$ in the $\mathrm{C}-\mathrm{H}$ stretching region of methyl group and $\mathrm{C}=\mathrm{O}$ stretching region was observed, respectively, from $S P$ and PLLA samples to $I P$ samples. The same behaviour was detected for the samples synthetized at the other mixing temperatures. The frequency shifts of the stretching vibration modes of the methyl and carbonyl groups confirmed that $I P$ samples contained stereocomplex of PLA according the literature [20].

On the other hand, no frequency shifts of the same peaks of $S P$ samples were observed comparing with the PLLA sample. As the $S P$ samples were obtained evaporating quickly the supernatant solution at room temperature in order to prevent both enantiomeric forms, PLLA and PDLA, from forming sc-PLA during

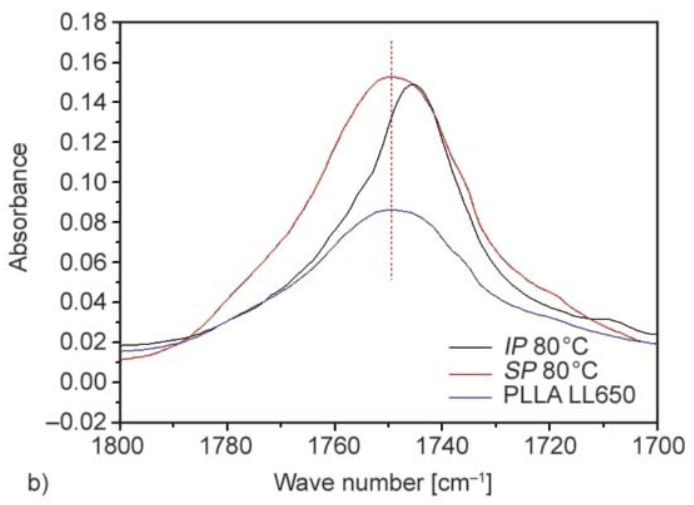

Figure 5. Changes of the IR spectra in the $\mathrm{C}-\mathrm{H}$ stretching region of methyl group (a) and $\mathrm{C}=\mathrm{O}$ stretching region (b) of the insoluble and soluble phase synthetized at $80^{\circ} \mathrm{C}$ and PLLA LL650 grade. 
the evaporation, the FT-IR results suggested that no sc-PLA is formed in the soluble phase during the evaporation.

\subsection{DSC and WAXS}

DSC thermograms of different precipitates from mixed solutions of PLLA and PDLA at various temperatures are given in Figure 6. The first heating at $10^{\circ} \mathrm{C} \cdot \mathrm{min}^{-1}$ was analysed to determine the crystallinity and the fusion behaviour of every samples.

On the DSC curve of the $I P$ precipitated at 25, 40 and $60^{\circ} \mathrm{C}$, a $T_{\mathrm{g}}$ transition was detectable around $80-85^{\circ} \mathrm{C}$. This result contrasted with the $T_{\mathrm{g}}$ value given in some papers, which reported that sc-PLA has a $T_{\mathrm{g}}$ value around $65-72{ }^{\circ} \mathrm{C}$ [36]. However, the precipitates synthetized at $80^{\circ} \mathrm{C}$ did not present the $T_{\mathrm{g}}$ transition. No cold crystallization peak was detectable during the heating scan for every precipitate. Only the melting peak of the racemic crystallites (sc-PLA crystallites) was observed around $230^{\circ} \mathrm{C}$ for every precipitate crystallized at $25,40,60$ and $80^{\circ} \mathrm{C}$. No fusion peak related to PLA homo-crystallites was detected.

On the other hand, the DSC curve of the polymeric sample that remained in solution during the experiment $(S P)$ only showed an endothermic peak around $177^{\circ} \mathrm{C}$ related to the fusion process of the PLA homo-crystallites. Therefore, this result confirmed again that no racemic crystallites were formed in the soluble phase an only the precipitates contained scPLA crystals.

The thermal characterization of the fusion peak of every sc-PLA formed at different temperatures of mixing is summarized at Table 5. The fusion peak temperature $\left(T_{\mathrm{m}}\right)$ was about $227-231^{\circ} \mathrm{C}$ without pointing a clear trend with the mixing temperature. On the other hand, a clear trend was observed in the



Figure 6. DSC thermograms of the precipitates from mixed solutions of PLLA and PDLA at 25, 40, 60 and $80^{\circ} \mathrm{C}$.
Table 5. Thermal characterization of the precipitates formed at various mixing temperatures.

\begin{tabular}{|c|c|c|c|c|}
\hline Sample & $\begin{array}{c}\boldsymbol{T}_{\mathbf{m}} \\
{\left[{ }^{\circ} \mathbf{C}\right]}\end{array}$ & $\begin{array}{c}\text { Onset } \boldsymbol{T}_{\mathbf{m}} \\
{\left[{ }^{\circ} \mathbf{C}\right]}\end{array}$ & $\begin{array}{c}\text { Peak width } \\
{\left[{ }^{\circ} \mathbf{C}\right]}\end{array}$ & $\begin{array}{c}\boldsymbol{X}_{\mathbf{C , s c}} \\
{[\mathbf{\%}]}\end{array}$ \\
\hline$I P$ at $25^{\circ} \mathrm{C}$ & 231.3 & 213.3 & 15.4 & 51.3 \\
\hline$I P$ at $40^{\circ} \mathrm{C}$ & 229.7 & 216.3 & 14.7 & 57.9 \\
\hline$I P$ at $60^{\circ} \mathrm{C}$ & 227.4 & 216.9 & 13.4 & 65.2 \\
\hline$I P$ at $80^{\circ} \mathrm{C}$ & 229.7 & 219.6 & 8.6 & 66.0 \\
\hline
\end{tabular}

other calorimetric parameters with rising the temperature of the solution. For example, the onset temperature of the fusion peak of the racemic crystallites increased with the mixing temperature, indicating that the stereocomplex crystallites are more thermally stable when they were prepared at higher solution temperatures, in agreement with Tsuji et al. [22]. Besides, the fusion peak width, which was calculated as the difference between the temperatures at 95 and 5\% of the peak area, decreased with forming the precipitates at higher temperatures, especially at $80^{\circ} \mathrm{C}$. Lower peak width could suggest higher homogeneity of crystal thickness. Finally, the sc-PLA crystallinity $\left(X_{\mathrm{C}, \mathrm{sc}}\right)$, which was calculated by Equation (1), increased with the mixing temperatures, almost reaching $70 \%$ of racemic crystallites over the total polymeric mass. According to Tsuji et al. [24], a decrease of the molecular weight could lead to an increase of the melting enthalpy of the racemic crystallites. Therefore, the decrease of the molecular weight that suffer the PLA specimens, particularly those synthesized at high temperatures, could be another factor to understand the DSC results.

Furthermore, some differences were detected in the profile of the fusion peak of the sc-PLA. The precipitates formed at 25,40 and $60^{\circ} \mathrm{C}$ had a melting profile with a fusion process or shoulder (peak $b$ ) before the main melting peak of sc-PLA (peak $a$ ). Peak $a$ is observed at almost the same temperature $\left(230^{\circ} \mathrm{C}\right)$ with identical shape, independent of the precipitation temperature, while peak $b$ became smaller, shifting to higher temperature with an increase in the precipitation temperature. The accompanying shoulders are not due to the crystallites of PDLA or PLLA but to the racemic crystallites, since peak $b$ did not disappear even after extracting the precipitates with fresh dioxane at $80^{\circ} \mathrm{C}$, in good agreement with literature data [25]. Precipitates formed at $80^{\circ} \mathrm{C}$ only showed peak $a$, denoting that with increasing the temperature of the polymer solution, more thermally stable racemic crystallites could be formed, probably, because higher 
chain mobility at higher temperatures allowed the polymer chains in the precipitate to reorganize to a more stable state, resulting in a higher degree of crystallinity. Each precipitate was analysed on DSC three times.

Tsuji et al. [25] studied the fusion profile of precipitates synthetized at different temperatures in acetonitrile solutions with low molecular weight PLA $\left(25 \mathrm{~kg} \cdot \mathrm{mol}^{-1}\right)$. We obtained similar results in the fusion behaviour of high molecular weight PLA precipitates formed at various solution temperatures in dioxane.

WAXS patterns of different precipitates synthetized at various mixing temperatures are presented in Figure 7. The main peaks of PLLA annealed at $90^{\circ} \mathrm{C}$ for 1 hour appeared at $2 \theta$ values of $15,16.5$ and $19^{\circ}$. They fit with the results of the $\alpha$ form of PLLA crystallized in a pseudo-orthorhombic unit cell of dimensions: $a=1.07 \mathrm{~nm}, b=0.595 \mathrm{~nm}$, and $c=2.78 \mathrm{~nm}$, which contains two $10^{3}$ helices, in accordance with literature data $[29,37]$.

On the other hand, the most intense peaks of the precipitates were observed at $2 \theta$ values of 12,21 and $24^{\circ} \mathrm{C}$, which are the main characteristic peaks in WAXS patterns for sc-PLA and crystallized in a triclinic unit cell of dimensions: $a=0.916 \mathrm{~nm}, b=$ $0.916 \mathrm{~nm}, c=0.870 \mathrm{~nm}, \alpha=109.2^{\circ}, \beta=109.2^{\circ}$ and $\gamma=109.8^{\circ}$, in which L-lactide and D-lactide segments are parallel packed taking 31 helical conformation, in accordance to different literature data [37]. Other researchers propose a trigonal structure, which has been studied in detail by ${ }^{13} \mathrm{C}-\mathrm{NMR}[38,39]$.

No shifts were detected between the main peaks in the WAXS profile of the precipitates formed at different mixing temperatures. However, the peak area became higher with increasing the solution temperature,

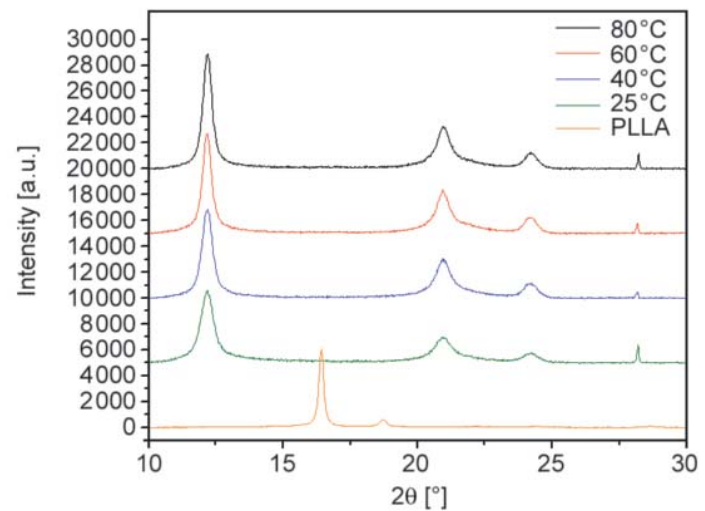

Figure 7. WAXS patterns of the precipitates from mixed solutions of PLLA and PDLA at $25,40,60$ and $80^{\circ} \mathrm{C}$ and annealed PLLA at $90^{\circ} \mathrm{C}$ for 1 hour. denoting that higher crystallinities could be obtained when the precipitates were formed at high temperatures. This experimental evidence fitted with the DSC results, which were analysed above.

\subsection{SEM observations}

The shape and size of the precipitates formed at various solution temperatures were analysed by SEM. The effect of crystallization temperature on the precipitate morphology is shown in Figure 8. The racemic precipitates were composed of spherical, porous and separated particles, regardless of the solution temperature. These results contrasted with the information reported by Tsuji et al. [22]. They studied the effect of the precipitation temperature on the morphology of precipitates formed in acetonitrile solutions of low molecular weight PLA, finding that at low temperatures the shape of the particles was indeed spherical, in contrast with the discoidal particles formed at $80^{\circ} \mathrm{C}$.

For all precipitates, the particle size ranged from 4 to 6 microns. As it can be seen in Figure 8, it is noteworthy to mention that the particle size of precipitates formed at $25^{\circ} \mathrm{C}$ was slightly bigger compared with the dimensions of the precipitates produced at higher temperatures, particularly at $80^{\circ} \mathrm{C}$. For each precipitate, the size dispersity was almost negligible. Finally, the precipitate synthesized at $80^{\circ} \mathrm{C}$ presented higher porosity than the precipitate formed at $25^{\circ} \mathrm{C}$. When the process was developed at high temperatures, the amount of $S P$ that remained in the system was higher than at low solution temperatures. Therefore, it is suggested that when the precipitate was cleaned with fresh dioxane and dried, the $S P$ extracted from the particles generated higher porosity on it. These particles are very close to that presented by Tsuji [22], which propose that they are spherulites of sc-PLA. Sheets observed in Figure $8\left(80^{\circ} \mathrm{C}\right)$ can be considered as lamellae being part of the spherulites. Particles precipitated at $25^{\circ} \mathrm{C}$ could be formed by highly crystalline spherulites and some amorphous sc-PLA that refills the pores between the lamellae. This explanation can be confirmed by DSC, which shows a slightly lower crystallinity for particles obtained at $25^{\circ} \mathrm{C}$ compared with those prepared at $80^{\circ} \mathrm{C}$.

\subsection{Heat resistance}

Nowadays, the conventional process to manufacture thermoplastic polymers are based on melt processing, 


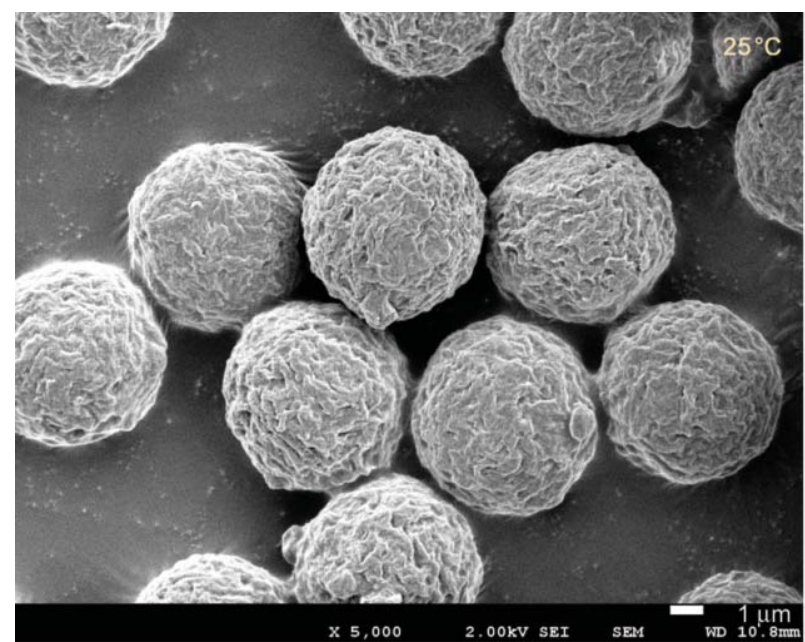

a)

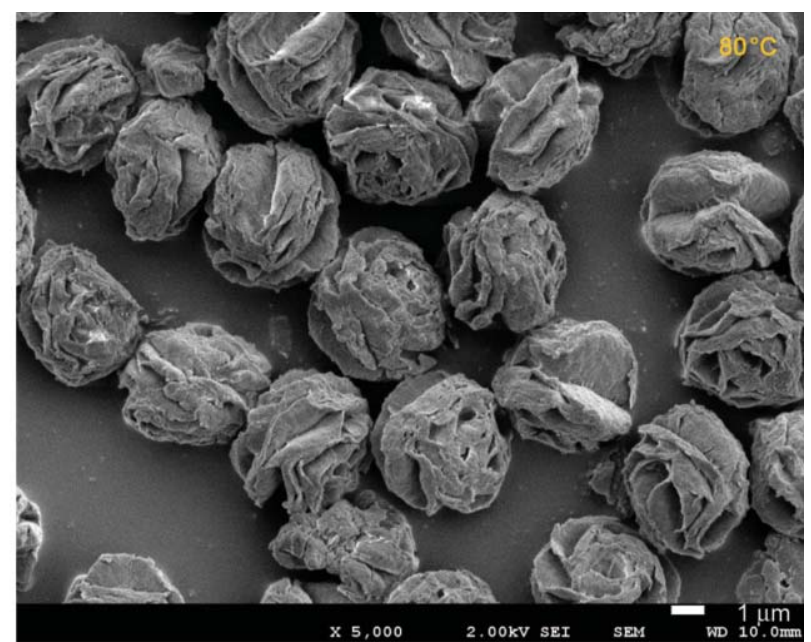

b)

Figure 8. Effect of the solution temperature on the morphology of the sc-PLA precipitates. Particles precipitated a) at $25^{\circ} \mathrm{C}$ and b) at $80^{\circ} \mathrm{C}$

which involves melting the polymer, shaping it to desired forms, and finally cooling it to stabilize the dimensions. However, melting the sc-PLA synthetized would imply losing the crystalline structure of the stereocomplex under inappropriate cooling conditions. Therefore, taking into account the study developed by Bai et al. [32], which suggested an alternative processing method for sc-PLA by low-temperature sintering, the bars of the different PLA precipitates used to measure the heat resistance were prepared by sintering.

The precipitates, in powder form, were sintered at $200^{\circ} \mathrm{C}$ and $20 \mathrm{MPa}$ for 15 minutes. Sc-PLA bars were thus obtained in order to measure the heat resistance of the PLA stereocomplex obtained in solution at various precipitation temperatures. The temperature to compress the samples was set $30^{\circ} \mathrm{C}$ lower than the melting temperature of the precipitates in order to prevent the sc-PLA crystallites from melting during processing. The results of heat resistance in terms of Vicat Softening Temperature are given in Table 6. The precipitates performed higher heat resistance than the bars of PLLA, amorphous or crystallized. Moreover, with increasing the precipitation temperature, an improvement of the heat resistance of the precipitates was observed, from 125 to $140^{\circ} \mathrm{C}$ for the sc-PLA synthetized at 25 and $60^{\circ} \mathrm{C}$, respectively. This evidence could be explained regarding the DSC results commented above (see Table 5).

These results suggested that more stable crystals and higher crystallinity in the precipitates were obtained at higher solution temperatures. Furthermore, no sintering of the particles of the precipitates formed at
Table 6. Heat resistance of sc-PLA precipitated at different solution temperatures. The heat resistance of PLLA is also shown.

\begin{tabular}{|l|c|}
\hline \multicolumn{1}{|c|}{ Sample } & $\begin{array}{c}\text { Vicat-B } \\
{\left[{ }^{\circ} \mathbf{C}\right]}\end{array}$ \\
\hline$I P 25^{\circ} \mathrm{C}$ & 125 \\
\hline$I P 40^{\circ} \mathrm{C}$ & 131 \\
\hline$I P 60^{\circ} \mathrm{C}$ & 140 \\
\hline$I P 80^{\circ} \mathrm{C}$ & Non sintered \\
\hline Amorphous PLLA & 60 \\
\hline Crystallized PLLA & $90-100$ \\
\hline
\end{tabular}

the highest temperature was observed even for compression times of 45 minutes, suggesting that the scPLA crystallites formed at $80^{\circ} \mathrm{C}$ are highly crystalline and stable. Finally, degradation of the molecular weight commented above did not negatively affect the heat resistance properties of the material.

\subsection{Capillary rheometry}

The IP formed at $25^{\circ} \mathrm{C}$ was tested in a capillary rheometer. It was intended to evaluate its potential processability in a conventional injection process without melting completely the racemic crystallites. The minimum temperature at which the material could flow through the capillary at the typical injection shear rate $\left(10000 \mathrm{~s}^{-1}\right)$ was $230^{\circ} \mathrm{C}$. Below this temperature, the material could not flow and pass through the capillary rheometer at same shear rate. Figure 9 shows the evolution of viscosity of the precipitate as a function of the apparent shear rate at $230^{\circ} \mathrm{C}$.

At $10000 \mathrm{~s}^{-1}$, the viscosity of the material was around $25 \mathrm{~Pa} \cdot \mathrm{s}$. A typical polypropylene (PP) viscosity value 


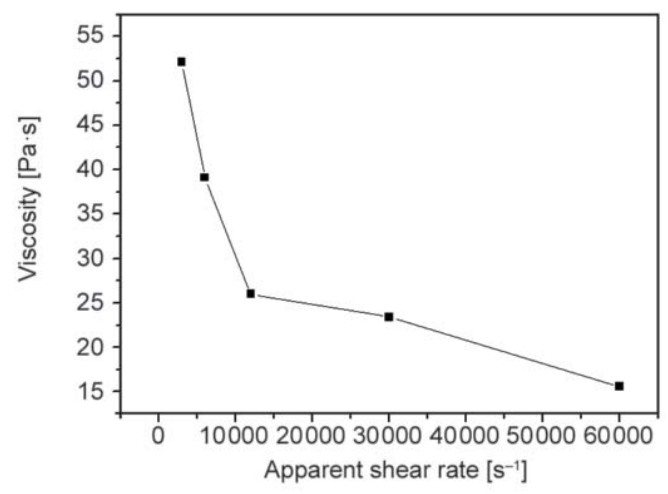

Figure 9. Evolution of the viscosity as function of the apparent shear rate at $230^{\circ} \mathrm{C}$.

at this shear rate is $18 \mathrm{~Pa} \cdot \mathrm{s}$. Even though the precipitates formed at $25^{\circ} \mathrm{C}$ presented higher viscosity than $\mathrm{PP}$, it is assumed that $I P$ formed at $25^{\circ} \mathrm{C}$ could be transformed by injection at $230^{\circ} \mathrm{C}$.

In order to know the degree of crystallinity that remained in the extruded material, a heating scan of the sample by DSC was performed (view Figure 10). As it can be observed on the extruded material curve, only the melting peak of the racemic crystallites (scPLA crystallites) was observed around $230^{\circ} \mathrm{C}$ and no fusion peak related to PLA homo-crystallites was detected. Moreover, comparing to the precipitate formed at $25^{\circ} \mathrm{C}$, the extruded material from the capillary rheometer performed similar degree of crystallinity, higher onset melting temperature and narrower melting peak width.

Furthermore, the shoulder related to less thermally stable crystals that were present in the $I P$ formed at $25^{\circ} \mathrm{C}$ did not appear in the extruded material. Therefore, this material seemed to perform better thermo-mechanical properties than its precursor material. It is believed that when the material passes through the capillary rheometer at $230{ }^{\circ} \mathrm{C}$, the more disordered

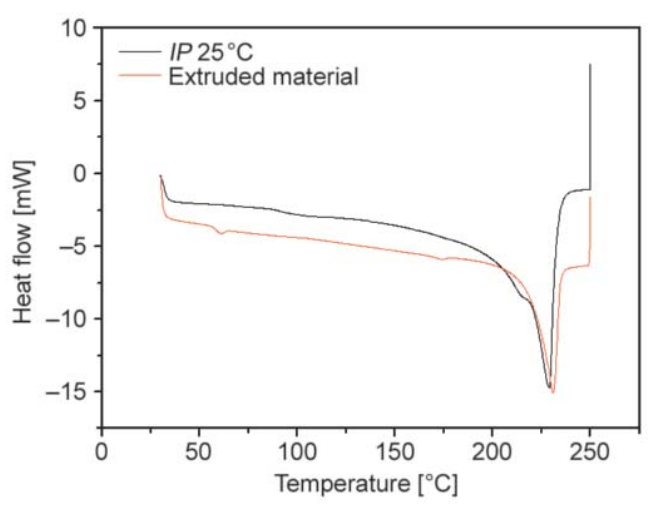

Figure 10. DSC thermogram of $I P$ formed at $25^{\circ} \mathrm{C}$ and the extruded material form the capillary rheometer.

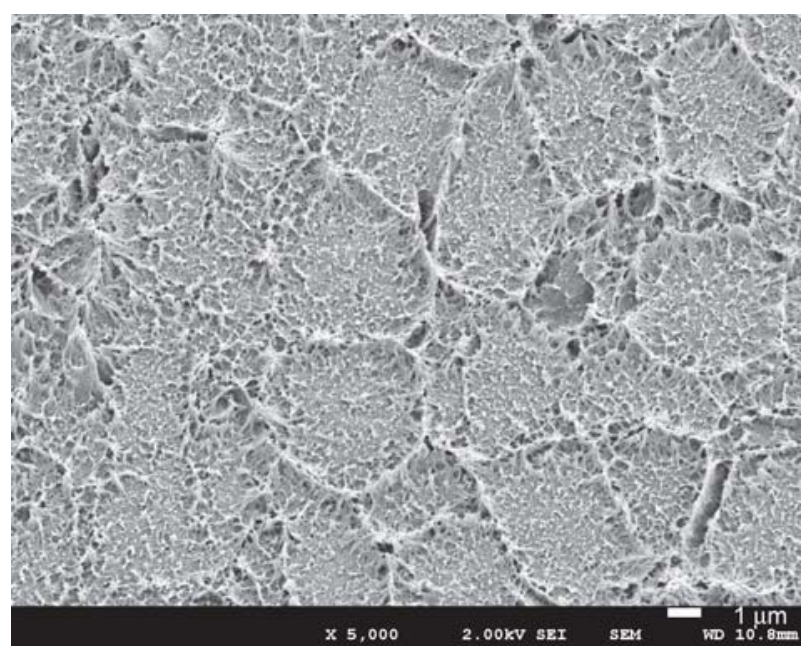

Figure 11. SEM image of the cross-section of the extruded material.

racemic crystallites melt and recrystallize to the more thermally stable racemic crystal form.

The SEM image in Figure 11 reveals the cross-section of the extruded material. It is observed that the particles has been welded, denoting a continuous phase. However, it is also detectable the boundaries of each particle.

Therefore, according to the results analysed above, it could be possible to transform the precipitates synthetized at $25^{\circ} \mathrm{C}$ by a conventional injection machine, maintaining or even improving its crystallization features and finally obtaining a $100 \%$ bio-based material with excellent heat resistance properties. Nevertheless, a deeper rheological study must be done to confirm what is suggested in this paper, and a high-controlled temperature process must be set to prevent the sc-PLA from melting.

\section{Conclusions}

This paper represented an attempt to assess the effect of the solution temperature on the formation of high molecular weight PLA stereocomplex.

All the precipitates synthetized in the temperature range from 25 to $80^{\circ} \mathrm{C}$ only consisted of sc-PLA without observing crystal phase separation between both homocrystals, PLLA and PDLA. In other words, the rate of nucleation and growth of the racemic crystallites is much higher than that of the crystallites of single polymers in dioxane at an initial concentration of $10 \mathrm{~g} \cdot \mathrm{dl}^{-1}$.

An increase of the solution temperature implied more thermally stable racemic crystallites because higher chain mobility at higher temperatures allowed the 
polymer chains in the precipitate to reorganize to a more stable state, resulting in a higher degree of crystallinity but also in a higher polymer degradation. The thermomechanical properties of the material also increased with the solution temperature, reaching a value of Vicat temperature as high as $140^{\circ} \mathrm{C}$.

However, lower sc-PLA formation rate and yield was obtained with increasing the solution temperature, particularly at $80^{\circ} \mathrm{C}$. The synthesis of the precipitates involves the nucleation and growth of the crystals, which were positively affected by temperature and the precipitation of the spherical particles, which was negatively affected by temperature.

Finally, the rheological results suggested that the precipitate formed at $25^{\circ} \mathrm{C}$ could be transformed in an injection machine at $230^{\circ} \mathrm{C}$ obtaining a $100 \%$ bio-based material with excellent heat resistance properties.

\section{Acknowledgements}

This work has been partially financed by Generalitat de Catalunya within the Industrial PhD Programme (DI 2014 0021 and by Spanish Ministry of Economy and Competitiveness (Program RETOS, Grant No. MAT2016-80045-R).

\section{References}

[1] Inkinen S., Hakkarainen M., Albertsson A-C., Södergård A.: From lactic acid to poly(lactic acid) (PLA): Characterization and analysis of PLA and its precursors. Biomacromolecules, 12, 523-532 (2004). https://doi.org/10.1021/bm101302t

[2] Gupta A. P., Kumar V.: New emerging trends in synthetic biodegradable polymers - Polylactide: A critique. European Polymer Journal, 43, 4053-4074 (2007). https://doi.org/10.1016/j.eurpolymj.2007.06.045

[3] Koenigsberg S., Willett A., Sutherland M.: Controlled release electron donors: Hydrogen release compound (HRC) - An overview of a decade of case studies. Bioremediation Journal, 10, 45-57 (2006). https://doi.org/10.1080/10889860600842837

[4] Gunasekara A. S., Xing B.: Sorption and desorption of naphthalene by soil organic matter. Journal of Environ Qualilty, 32, 240-246 (2003). https://doi.org/10.2134/jeq2003.2400

[5] Wang X., Yang K., Tao S., Xing B.: Sorption of aromatic organic contaminants by biopolymers: Effects of $\mathrm{pH}$, copper (II) complexation, and cellulose coating. Environmental Science and Technology, 41, 185-191 (2007). https://doi.org/10.1021/es061389e

[6] Witzke D. R.: Introduction to properties engineering and prospects of polylactide polymers. PhD thesis. Michigan State University (1997).
[7] Bigg D. M.: Polylactide copolymers: Effect of copolymer ratio and end capping on their properties. Advances in Polymer Technology, 24, 69-82 (2005).

https://doi.org/10.1002/adv.20032

[8] Saeidlou S., Huneault M. A., Li H., Park C. B.: Poly (lactic acid) crystallization. Progress in Polymer Science, 37, 1657-1677 (2012).

https://doi.org/10.1016/j.progpolymsci.2012.07.005

[9] Kolstad J. J.: Crystallization kinetics of poly(L-lactideco-meso-lactide). Journal of Applied Polymer Science, 62, 1079-1091 (1996).

https://doi.org/10.1002/(SICI)10974628(19961114)62:7<1079::AID-APP14>3.0.CO;2-1

[10] Hartmann M.: High molecular weight polylactic acid polymers. in 'Biopolymers from renewable resources' (ed.: Kaplan D.) Springer, Berlin, 367-411 (1998).

[11] Sun Q-S., Dong J., Lin Z-X., Yang B., Wang J-Y.: Comparison of cytocompatibility of zein film with other biomaterials and its degradability in vitro. Biopolymers, 78, 268-274 (2005). https://doi.org/10.1002/bip.20298

[12] Seifert B., Romaniuk P., Groth T.: Covalent immobilization of hirudin improves the haemocompatibility of polylactide-polyglycolide in vitro. Biomaterials, 18, 1495-1502 (1997).

https://doi.org/10.1016/S0142-9612(97)00079-3

[13] Ignjatović N., Savić V., Najman S., Plavšić M., Uskoković D.: A study of HAp/PLLA composite as a substitute for bone powder, using FT-IR spectroscopy. Biomaterials, 22, 571-575 (2001). https://doi.org/10.1016/S0142-9612(00)00215-5

[14] Cosme J. G. L., Silva V. M., Nunes R. R. C., Picciani P. H. S.: Development of biobased poly(lactic acid)/ epoxidized natural rubber blends processed by electrospinning: Morphological, structural and thermal properties. Materials Sciences and Applications, 7, 66003/166003/10 (2016). https://doi.org/10.4236/msa.2016.74021

[15] Nekhamanurak B., Patanathabutr P., Hongsriphan N.: The influence of micro-/nano- $\mathrm{CaCO}_{3}$ on thermal stability and melt rheology behavior of poly(lactic acid). Energy Procedia, 56, 118-128 (2014). https://doi.org/10.1016/j.egypro.2014.07.139

[16] Li H., Huneault M. A.: Effect of nucleation and plasticization on the crystallization of poly(lactic acid). Polymer, 48, 6855-6866 (2007).

https://doi.org/10.1016/j.polymer.2007.09.020

[17] Androsch R., Di Lorenzo M. L.: Kinetics of crystal nucleation of poly(L-lactic acid). Polymer, 54, 6882-6885 (2013). https://doi.org/10.1016/j.polymer.2013.10.056

[18] Nam J. Y., Sinha R. S., Okamoto M.: Crystallization behavior and morphology of biodegradable polylactide/ layered silicate nanocomposite. Macromolecules, 36, 7126-7131 (2003). https://doi.org/10.1021/ma034623j 
[19] Shi X., Zhang G., Phuong T. V., Lazzeri A.: Synergistic effects of nucleating agents and plasticizers on the crystallization behavior of poly(lactic acid). Molecules, 20, 1579-1593 (2015). https://doi.org/10.3390/molecules20011579

[20] Zhang J., Sato H., Tsuji H., Noda I., Ozaki Y.: Infrared spectroscopic study of $\mathrm{CH}_{3} \cdot \mathrm{OC}$ interaction during poly (L-lactide)/poly(D-lactide) stereocomplex formation. Macromolecules, 38, 1822-1828 (2005).

https://doi.org/10.1021/ma047872w

[21] Zhang J., Sato H., Tsuji H., Noda I., Ozaki Y.: Differences in the $\mathrm{CH}_{3} \cdots \mathrm{OC}$ interactions among poly(L-lactide), poly(L-lactide)/poly(D-lactide) stereocomplex, and poly(3-hydroxybutyrate) studied by infrared spectroscopy. Journal of Molecular Structure, 735, 249-257 (2005). https://doi.org/10.1016/j.molstruc.2004.11.033

[22] Tsuji H., Hyon S. H., Ikada Y.: Stereocomplex formation between enantiomeric poly(lactic acids). 5. Calorimetric and morphological studies on the stereocomplex formed in acetonitrile solution. Macromolecules, 25, 2940-2946 (1992). https://doi.org/10.1021/ma00037a024

[23] Tsuji H., Hyon S. H., Ikada Y.: Stereocomplex formation between enantiomeric poly (lactic acid)s. 3. Calorimetric studies on blend films cast from dilute solution. Macromolecules, 24, 5651-5656 (1991). https://doi.org/10.1021/ma00020a026

[24] Tsuji H., Hyon S. H., Ikada Y.: Stereocomplex formation between enantiomeric poly(lactic acid)s. 4. Differential scanning calorimetric studies on precipitates from mixed solutions of poly(D-lactic acid) and poly(L-lactic acid). Macromolecules, 24, 5657-5662 (1991). https://doi.org/10.1021/ma00020a027

[25] Tsuji H., Horii F., Hyon S. H., Ikada Y.: Stereocomplex formation between enantiomeric poly(lactic acid)s. 2 . Stereocomplex formation in concentrated solutions. Macromolecules, 24, 2719-2724 (1991). https://doi.org/10.1021/ma00010a013

[26] Andersson S. R., Hakkarainen M., Inkinen S., Södergåd A., Albertsson A-C.: Customizing the hydrolytic degradation rate of stereocomplex PLA through different PDLA architectures. Biomacromolecules, 13, 1212 1222 (2012). https://doi.org/10.1021/bm300196h

[27] Fujita M., Sawayanagi T., Abe H., Tanaka T., Iwata T., Ito K., Maeda M.: Stereocomplex formation through reorganization of poly(L-lactic acid) and poly(D-lactic acid) crystals. Macromolecules, 41, 2852-2858 (2008). https://doi.org/10.1021/ma7024489

[28] Shen L., Haufe J., Patel M. K.: Product overview and market projection of emerging bio-based plastics $\mathrm{PRO}$ BIP 2009. Report for European polysaccharide network of excellence and European bioplastics (2009).
[29] Tsuji H.: Poly(lactide) stereocomplexes: Formation, structure, properties, degradation, and applications. Macromolecular Bioscience, 5, 569-597 (2005). https://doi.org/10.1002/mabi.200500062

[30] Tsuji H., Ikada Y.: Stereocomplex formation between enantiomeric poly(lactic acids). 9. Stereocomplexation from the melt. Macromolecules, 26, 6918-6926 (1993). https://doi.org/10.1021/ma00077a032

[31] Bouapao L., Tsuji H.: Stereocomplex crystallization and spherulite growth of low molecular weight poly(Llactide) and poly(D-lactide) from the melt. Macromolecular Chemistry and Physics, 210, 993-1002 (2009). https://doi.org/10.1002/macp.200900017

[32] Bai D., Liu H., Bai H., Zhang Q., Fu Q.: Powder metallurgy inspired low-temperature fabrication of highperformance stereocomplexed polylactide products with good optical transparency. Scientific Reports, 6, 20260/1-20260/9 (2016).

https://doi.org/10.1038/srep20260

[33] Tsuji H., Fukui I.: Enhanced thermal stability of poly (lactide)s in the melt by enantiomeric polymer blending. Polymer, 44, 2891-2896 (2003). https://doi.org/10.1016/S0032-3861(03)00175-7

[34] Elsawy M. A., Kim K-H., Park J-W., Deep A.: Hydrolytic degradation of polylactic acid (PLA) and its composites. Renewable and Sustainable Energy Reviews, 79, 1346-1352 (2017). https://doi.org/10.1016/j.rser.2017.05.143

[35] Lorenzo A. T., Arnal M. L., Albuerne J., Müller A. J.: DSC isothermal polymer crystallization kinetics measurements and the use of the Avrami equation to fit the data: Guidelines to avoid common problems. Polymer Testing, 26, 222-231 (2007). https://doi.org/10.1016/j.polymertesting.2006.10.005

[36] Perego G., Cella G. D., Bastioli C.: Effect of molecular weight and crystallinity on poly(lactic acid) mechanical propertiess. Journal of Applied Polymer Science, 59, 37-43 (1996).

https://doi.org/10.1002/(SICI)10974628(19960103)59:1<37::AID-APP6>3.0.CO;2-N

[37] Okihara T., Tsuji M., Kawaguchi A., Katayama K-I., Tsuji H., Hyon S-H., Ikada Y.: Crystal structure of stereocomplex of poly(L-lactide) and poly(D-lactide). Journal of Macromolecular Science Part B: Physics, 30, 119-140 (1991). https://doi.org/10.1080/00222349108245788

[38] Cartier L., Okihara T., Lotz B.: Triangular polymer single crystals: Stereocomplexes, twins, and frustrated structures. Macromolecules, 30, 6313-6322 (1997). https://doi.org/10.1021/ma9707998

[39] Zhou W., Wang K., Wang S., Yuan S., Chen W., Konishi T., Miyoshi T.: Stoichiometry and packing structure of poly(lactic acid) stereocomplex as revealed by solidstate NMR and ${ }^{13} \mathrm{C}$ isotope labeling. ACS Macro Letters, 7, 667-671 (2018).

https://doi.org/10.1021/acsmacrolett.8b00297 